\section{Evaluation and validation of an alternative method to detect Campylobacter spp. in dairy products}

\author{
Elisabetta Razzuoli, Walter Vencia, \\ Valeria Fedele, Giulia Mignone, \\ Fabrizio Lazzara, Danja Rubini, \\ Guendalina Vito, Chiara Porcario, \\ Elena Bozzetta, Angelo Ferrari
}

Food Control Laboratory, Experimental Zooprophylactic Institute of Piemonte, Liguria and Valle d'Aosta, Genoa, Italy

\begin{abstract}
Foods implicated in human campylobacteriosis include raw or undercooked poultry and raw dairy products. Because Campylobacter spp. are the most frequently reported cause of bacterial infection in the European Union and because conventional methods are cumbersome, rapid methods for Campylobacter detection and quantification in food are needed. With this study we sought to validate, according to the standard procedure (UNI EN ISO 16140:2003), an alternative to the reference analytical method (UNI EN ISO 102721:2006) for official controls of Campylobacter spp. in raw milk and dairy products. Milk samples collected from 16 milk vending machines located throughout the Genoa metropolitan area were analyzed using two different methods, an enzymelinked fluorescent assay (ELFA) and a real-time PCR assay, and evaluated in parallel against the reference method. In addition, a total of 460 samples of raw milk collected from milk vending machines were analyzed by ELFA. Results obtained with ELFA showed it was compliant with UNI EN ISO 10272-1:2006 criteria and that the immunoassay had $100 \%$ sensitivity, specificity, and accuracy. Regarding samples of milk vending machines, $5.0 \%$ (23/460) tested positive at ELFA screening and were subsequently confirmed as $C$. jejuni. Validation according to UNI EN ISO 16140:2003 of the ELFA method suggests it may be a useful alternative to conventional methods for detecting Campylobacter spp. in official controls.
\end{abstract}

\section{Introduction}

Campylobacter spp. are recognized as the bacterial agent responsible for campylobacteriosis, a zoonotic disease.
According to the latest report of the European Food Safety Authority (EFSA), campylobacteriosis is the most frequently reported human gastrointestinal bacterial infection in the European Union (EU): in 2016 about 246,000 human cases were reported, incrementing of $6.1 \%$ the cases than 2015. Furthermore, 461 foodborne outbreaks were reported in Europe in 2016 with 4606 outbreak-related cases (EFSA and ECDC, 2017).

Campylobacters are transmitted via the oral-fecal route, mainly by the ingestion of contaminated food or water. The species most commonly associated with human infections are Campylobacter jejuni, followed by C. coli, and C. lari, though other species, including the non-thermophilic $C$. fetus, have occasionally been reported to cause human diseases (EFSA, 2015; Rodrigues et al., 2015).

Recent trends in food consumption indicate an increasing preference for local products (short food supply chain) and a growing demand for fresh or minimally processed food products as well as meals ready-to-eat (EFSA Journal 2012). The increasing incidence of foodborne bacterial infections is thought to be related to these trends (EFSA Journal, 2015). Foods implicated in campylobacteriosis include raw or undercooked poultry and raw dairy products. In this respect, at EU level 1896 sampled units were analyzed to detect Campylobacter spp. in milk and milk products (including cheeses) in 2016 with the occurrence around $1 \%$. In the outbreaks associated with the consumption of milk, cheese and dairy products Campylobacter was the causative agent with strong-evidence (22.2\%) (EFSA and ECDC, 2017).

The risk of infection is high due to the minimum infecting dose of 500 colonyforming units (CFU)/sample (Stern and Robach, 2003). While pasteurization inactivates Campylobacter spp. in few seconds, the bacterium is quite resistant to lower temperatures, indeed they are able to survive for several weeks in refrigerated milk and water (Haughton et al., 2012).

The reference analytical method for the detection of Campylobacter spp. in dairy products is UNI EN ISO 10272-1:2006, a classical four-step plate isolation procedure that entails sample preparation, isolation, confirmatory testing (Morphology/Motility, Oxidase, Microaerobic growth at $25^{\circ} \mathrm{C}$, Aerobic growth at $41,5^{\circ} \mathrm{C}$ ), and bacterial identification (Catalase, Hippurate, Indoxyl acetate, Nalidixic acid, Cephalothin). Conventional detection methods are slow and may lack in accuracy because of the complex growth requirements of Campylobacter (Melero et al., 2011)
Correspondence: Walter Vencia, Food Control Laboratory, Experimental Zooprophylactic Institute of Piemonte, Liguria e Valle d'Aosta, Piazza Borgo Pila 39-24, 16129 Genoa, Italy. Tel.: +39.010.542274.

E-mail: walter.vencia@izsto.it

Key words: Campylobacter spp., ELFA, RTPCR, Validation, Dairy products, ISO 16140:2003.

Contributions: the authors contributed equally.

Conflict of interest: the authors declare no potential conflict of interest.

Funding: none

Received for publication: 26 January 2018. Revision received: 23 February 2018. Accepted for publication: 21 March 2018

This work is licensed under a Creative Commons Attribution-NonCommercial 4.0 International License (CC BY-NC 4.0).

(C) Copyright E. Razzuoli et al., 2018

Licensee PAGEPress, Italy

Italian Journal of Food Safety 2018; 7:7180

doi:10.4081/ijfs.2018.7180

involving prolonged incubation time and selective enrichment to reduce the development of background flora. Moreover, test sensitivity, especially in milk samples, is reduced due to improper sample handling, transport, and storage conditions, which inevitably affect strain viability. Alternative detection procedures such as enzyme-linked immunoassay and/or molecular tests are needed to detect foodborne pathogens more rapidly and accurately and ensure food safety. As stated by EC Regulation No $2073 / 2005$, the use of alternative analytical methods may be authorized if they are validated according to UNI EN ISO 16140:2003 or other internationally accepted protocols. ISO 16140:2003 establishes the general principle and technical characteristics for the validation of alternative methods for the microbiological analysis of food, animal feeding stuff, and environmental and animal specimens. The two step-process entails: validation of alternative methods for use in official controls; and international approval of the results obtained by the alternative method. Diverse real-time PCR assays have been developed to detect Campylobacter spp. in chicken carcasses (Botteldoorn et al., 2008), fresh chicken meat and by-products (Saiyudthong et al., 2015), and foods (Vencia et al., 2014). Although an alternative AOAC-certified procedure to detect 
Campylobacter from chicken carcass and carcass sponges from turkey is available, currently there are few alternative methods for the detection of Campylobacter spp. in dairy products. Such alternative methods are mainly PCR based methods with high sensitivity and low specificity; this cause increase of analysis time.

ELFA method was investigated in different study for detection of several foodborne pathogens. ELFA method is reported as alternative procedure to detect Salmonella spp. in raw chicken meat (Rohonczy et al., 2014), Listeria monocytogenes in various food samples (Ueda and Kuwabara, 2010), Escherichia coli O157 in mincemeat (Stefan et al., 2007).

The aim of this study was to evaluate an alternative method to UNI EN ISO 102721:2006 that could improve the performance of Campylobacter spp. diagnostic protocols by reducing analysis time. Afterward the method with high performances was validated, according to the standard procedure (UNI EN ISO 16140:2003).

\section{Materials and Methods}

\section{Study design}

Two different methods were evaluated in parallel against the reference method (UNI EN ISO 10272-1:2006), an enzyme-linked fluorescent assay (ELFA) and a real-time PCR assay, in milk samples collected from 16 milk vending machines throughout the Genoa metropolitan area. Three milk samples testing negative for Campylobacter were spiked with a $50 \mathrm{CFU} / \mathrm{mL}$ suspension of Campylobacter jejuni (ATCC 29428). Each sample was divided into 11 aliquots and stored at $4 \pm 2{ }^{\circ} \mathrm{C}$. An aliquot of each sample was used for $\mathrm{pH}$ control; the others were kept refrigerated: T0 (baseline), T1 (1 h), T6 (6 h), T24 (24 h), T30 (30 h), T48 (48 h), T144 (6 days), T192 (8 days), T240 (10 days), and T312 (13 days). Refrigeration temperature and times were based on published data (Jinlin et al., 2011). The samples were processed with enrichment as it follows: $25 \mathrm{~mL}$ of milk was placed in Campylobacter enrichment broth (CEB) (Biolife, Milan, Italy, cod. 401286B) supplemented with $12.5 \mathrm{~mL}$ of horse blood lysate (Biolife, cod. 90HLX100) and $2.5 \mathrm{~mL}$ of Campylobacter Bolton selective supplement (Microbiol, Uta-Cagliari, Italy, cod. 76147), and incubated under microaerophilic conditions at $37 \pm 1{ }^{\circ} \mathrm{C}$ for 4 $6 \mathrm{~h}$ and then at $41.5 \pm 1{ }^{\circ} \mathrm{C}$ for $44 \pm 4 \mathrm{~h}$ using jars with atmosphere generation system (CampyGen Oxoid ${ }^{\mathrm{TM}}$, Oxoid Ltd, Basingstoke, UK, cod. CN0035A). The samples were analyzed using the three analytical methods to detect Campylobacter spp. (Table 1).

\section{ISO (UNI EN ISO 10272-1:2006) reference method}

The reference analytical method represents a classical four-step procedure for Campylobacter spp. detection and enumeration in food and animal feeding stuffs: 1) sample preparation, 2) enrichment, 3 ) isolation, and 4) confirmatory testing. In order to detect the presence of colonies likely referable to Campylobacter spp., enrichment is followed by seeding the sample on plates of modified charcoal cefoperazonedeoxycholate agar (mCCDA) and Campy Food Agar (CFA) incubated in microaerobic conditions at $41.5 \pm 1{ }^{\circ} \mathrm{C}$. Suspected colonies are selected from each plate, seeded in Columbia agar, and incubated in microaerophilic conditions at $41.5 \pm 1{ }^{\circ} \mathrm{C}$. These pure cultures are then used to confirm the presence of Campylobacter spp. by the following assays: a) typical bacteria morphology and motility test; b) incubation at $25 \pm 1^{\circ} \mathrm{C}$ in microaerobiosis for about $44 \pm 4 \mathrm{~h}$; c) incubation at $41.5 \pm 1{ }^{\circ} \mathrm{C}$ in aerobiosis for approximately $44 \pm 4 \mathrm{hs}$; d) oxidase test. The presence of Campylobacter spp. is confirmed based on: positive oxidase reaction, typical motility and morphology, absence of growth at $25^{\circ} \mathrm{C}$ in microaerobiosis and at $41.5^{\circ} \mathrm{C}$ in aerobiosis.

Table 1. Details of the aliquots analyzed and analytical methods applied (h: hours of refrigeration): 3 milk samples spiked with Campylobacter jejuni.

$\begin{array}{ll}\text { Aliquots for each sample } & \text { Analytical methods } \\ \text { pH control } & \\ \text { T0 (baseline) } & \\ \text { T1 (1h) } & \\ \text { T6 (6h) } & \text { ISO (UNI EN ISO 10272-1:2006) Reference Method } \\ \text { T24 (24h) } & \text { Real-Time PCR } \\ \text { T30 (30h) } & \text { Enzyme-Linked Fluorescent Assay (ELFA) } \\ \text { T48 (48h) } & \\ \text { T144 (6 days) } & \\ \text { T192 (8 days) } & \\ \text { T240 (10 days) } & \\ \text { T312 (13 days) } & \end{array}$

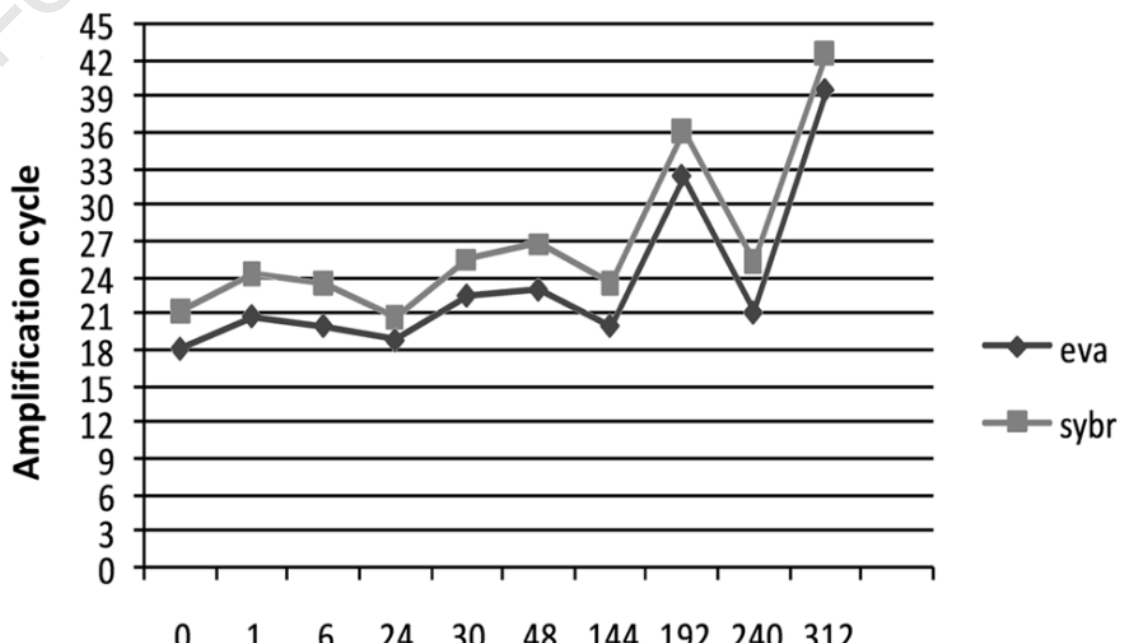

Hours of refrigeration

Figure 1. Comparison between fluorophores. Data are expressed as arithmetic means of the amplification cycles $(\mathrm{Ct})$ detected by the two fluorophores tested at different hours of refrigeration: EvaGreen showed greater sensitivity (eva: EvaGreen; sybr: SYBRGreen). 


\section{Real-Time PCR}

DNA was extracted in $1 \mathrm{~mL}$ of the enrichment broth using a QIAamp Mini kit ${ }^{\circledR}$ (Qiagen ${ }^{\circledR}$, Milan, Italy, cat. 51306) following the manufacturer's recommendations. For the real-time PCR assay, amplification of a specific gene of $C$. jejuni gene encoding hippuricase was performed using the primers (F:5'CGGGATAGTTATAGTATTGAAGTT ATTGG3';R:5'GAAGGAGCATAATAGGA TCTTG3') (Zhang et al., 2013) and two different amplification mixes based on SYBR Green ${ }^{\circledR}$ (RealMasterMix Fast SYBR ${ }^{\mathrm{TM}}$ 2X, 5Prime, ThermoFisher Scientific, Rodano, Italy) and EvaGreen ${ }^{\circledR}$ (SsoFast ${ }^{\mathrm{TM}}$ EvaGreen ${ }^{\circledR}$ Supermix, Bio-Rad Laboratories, Milan, Italy), respectively; two DNA intercalators widely used in molecular biology as an alternative to the classical system of the probe (Razzuoli et al., 2011) were applied. Amplification was carried out on a CFX96 ${ }^{\mathrm{TM}}$ real-time PCR system (Bio$\mathrm{Rad}$ ) using the temperature profile described in Razzuoli et al., 2013.

\section{Enzyme-linked fluorescent assay (ELFA)}

ELFA is an immunological analytical method that detects antigens and measures the concentration of antibodies in blood plasma. Among the different immunoassay methods, ELFA refers to heterogeneous phase systems in which the antibodies or antigens are adsorbed or bound to a solid substrate (O'Keeffe et al., 2000). The ELFA based on commercial instrument is entirely automated and it is associated ready to use kits. The total enrichment time is $44-52 \mathrm{~h}$ and the time of run is 70 minutes (bioMérieux, France). In the present study, the ELFA MiniVIDAS ${ }^{\circledR}$ Campylobacter kit (ELFA CAM) (bioMèrieux, Marcy l'Etoile, France, cat. 30111) was used according to the manufacturer's instructions, with slight modifications: Bolton broth was prepared according to UNI EN ISO 10272-1:2006 for the enrichment step instead of the suggested enrichment broth.

\section{Statistical analysis}

Each test was performed in triplicate. The results obtained by the culture method are expressed qualitatively as presence/absence. For the molecular methods, the microbial challenge tests were normalized by adding 4 ng of DNA to each amplification reaction. Results are expressed as the mean $\mathrm{Ct}$ amplification and Delta $\mathrm{Ct}$ (Ct at time 0 - $\mathrm{Ct}$ refrigeration time) (Talaat et al., 2002). The results obtained with the ELFA method are expressed in TV (relative
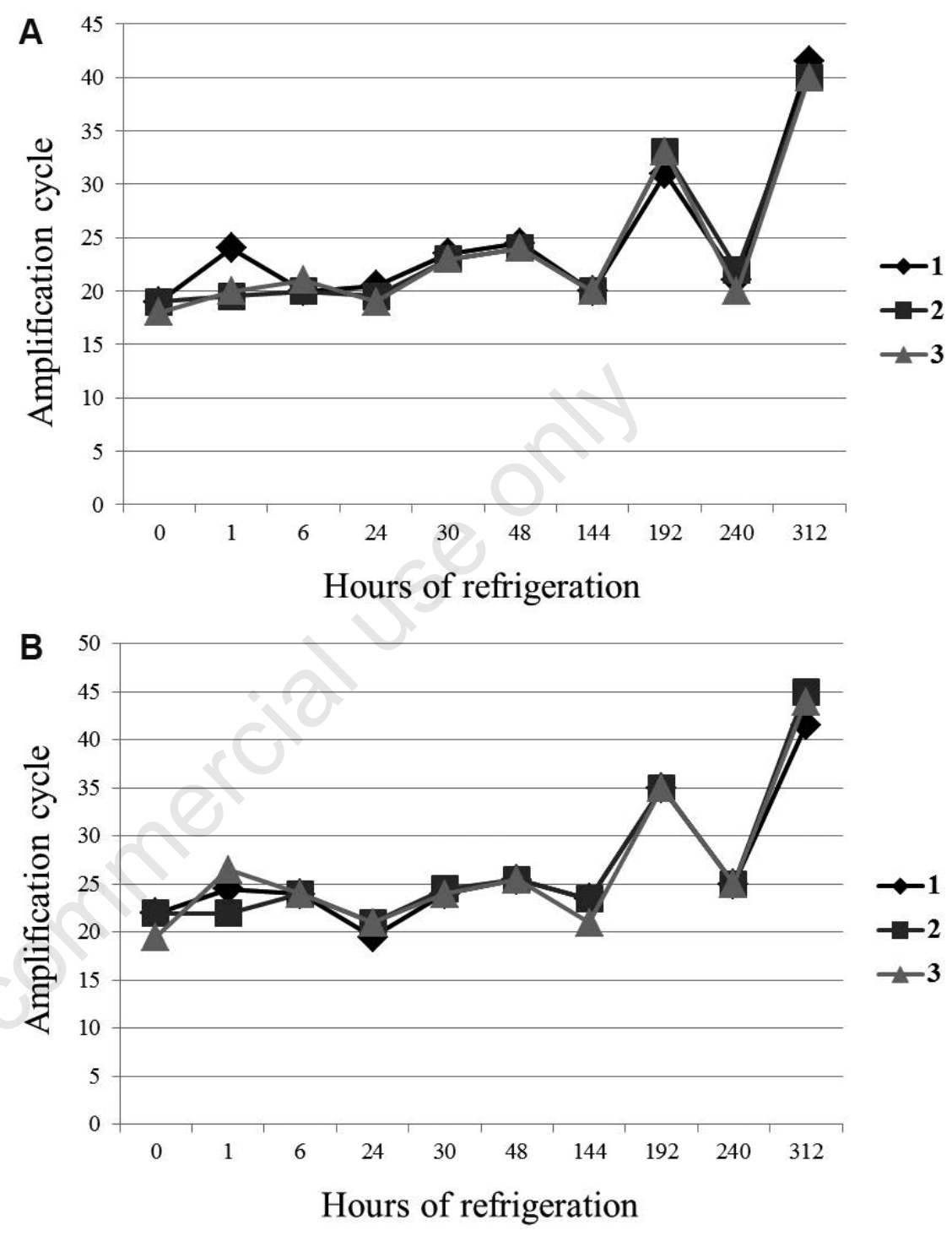

Figure 2. Performance of 3 dropped samples. The increase in amplification cycle $(\mathrm{Ct})$ indicates a decrease in Campylobacter concentration. Data are expressed as the arithmetic means of the Ct of the 3 samples. A) Test using EvaGreen. B) Test using SYBRGreen.

Table 2. Details of validation protocol; determination of limit of detection (LOD), relative sensitivity, accuracy, specificity, relative detection level. All samples were tested by ELFA and reference analytical method.

\begin{tabular}{|c|c|c|c|c|c|c|c|c|c|c|}
\hline LOD & & & serial dilut & & & & & & & \\
\hline $\mathrm{CFU} / \mathrm{mL}$ & $1.5^{*} 107$ & $1.5^{*} 10^{6}$ & $1.5^{*} 10^{5}$ & $1.5^{*} 10^{4}$ & $1.5^{*} 10^{3}$ & 150 & 15 & 10 & 5 & $1 \quad 0.25$ \\
\hline & $1 \mathrm{mLl}$ & terial st & pension + & illk sam & le & & & & & \\
\hline Sensitivity specificity accuracy (tot 104 samples) & $10 \mathrm{sal}$ & & 13 samples & & 15 samples & & & amples & & 59 samples \\
\hline Spiked level & equal to & LOD & LOD*10 & & LOD*20 & & & D*100 & & negative \\
\hline Relative detection level (tot 18 samples) & $6 \mathrm{san}$ & & 6 samples & & 6 samples & & & - & & - \\
\hline Spiked level & equal to & LOD & LOD*3 & & negative & & & - & & - \\
\hline
\end{tabular}


fluorescence values of the sample/relative fluorescence values of positive control). Samples with TV $>0.10$ were considered as positive. Within the same group (method detecting presence/absence of Campylobacter), the differences between the means were evaluated using ANOVA (GraphPad Prism 5.03, GraphPad Software, San Diego, CA, USA). The threshold of significance was set at $0.05(\mathrm{P}<0.05)$.

\section{Validation protocol}

Validation according to the standard procedure (UNI EN ISO 16140:2003) of a qualitative method alternative to a reference method is allowed. Two alternative methods to the reference analytical method (UNI EN ISO 10272-1:2006) for the detection of Campylobacter in milk were compared to determine: limit of detection (LOD), relative sensitivity, accuracy, specificity, relative detection level, inclusiveness, and exclusivity. In order to assess the LOD, serial dilutions were prepared from a suspension of C. jejuni (ATCC 29428) 0.5 McFarland (corresponding to $1.5 * 10^{8} \mathrm{CFU} / \mathrm{mL}$ ) in physiological solution. A total of 13 serial dilutions were prepared at concentrations of: $1.5 * 10^{7}, 1.5 * 10^{6}, 1.5 * 10^{5}, 1.5^{*} 10^{4}, 1.5^{*} 10^{3}$, $150,15,10,5,2,1,0.5$, and $0.25 \mathrm{CFU} / \mathrm{mL}$. A raw milk sample testing negative for Campylobacter according to the classical method was used to determine the LOD. Each sample was contaminated with $1 \mathrm{~mL}$ of a bacterial suspension previously prepared and tested by both the ELFA and the reference analytical method. Method sensitivity, specificity, and accuracy were tested in total of 104 samples of milk and dairy products: 70 milk samples and 34 cheese samples, 45 of which were artificially contaminated with $C$. jejuni. Comparison tests were performed on these 45 samples: 10 samples spiked with a concentration equal to the LOD,13 at LOD*10, 15 at LOD*20, and 7 at LOD*100. In addition, the relative detection level was tested in 18 raw milk samples: 6 spiked with a concentration equal to the LOD, 6 at LOD*3, and 6 testing negatives for Campylobacter (Table 2). In compliance with UNI EN ISO 16140:2003, each LOD was compared using Fisher's exact test (PrismGraphPad 5.03).

\section{Naturally contaminated sample analysis}

Between 1 January 2014 and 31 December 2016, the ELFA method was used in our laboratory to analyze raw milk samples collected from milk vending machines. A total of 460 samples were analyzed; all positive samples were confirmed by the reference analytical method.

\section{Results and Discussion}

The results of the molecular biology tests support the hypothesis that both fluorophores correctly detected the presence of bacterial genomes (T0 to T312). EvaGreen showed greater sensitivity than SYBRGreen; a difference of $3 \pm 1.09$ in $\mathrm{Ct}$ indicated an equal DNA concentration in all samples (Figure 1). No differences in $\mathrm{Ct}$ with respect to refrigeration time were observed (Figure 2). This is consistent with previously published data and was probably due to the higher affinity of EvaGreen for dsDNA, which yields higher fluorescence signals (Razzuoli et al., 2011). Moreover, Campylobacter spp. DNA could still be detected at T312 (13 days of refrigeration) but there was no colony growth on the plate,

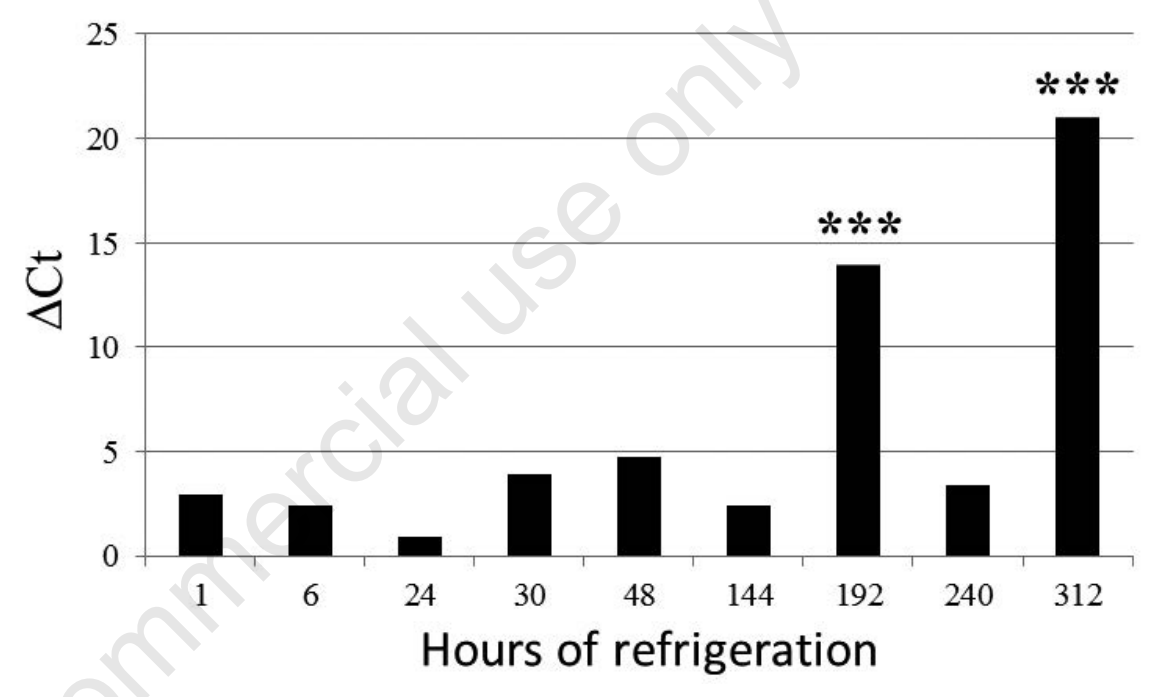

Figure 3. Change in $\mathrm{Ct}$ in relation to refrigeration time. $\Delta \mathrm{Ct}=$ difference between $\mathrm{TX}$ and T0. ${ }^{* * *}$ Statistically significant $\mathrm{P}<0.0001$.

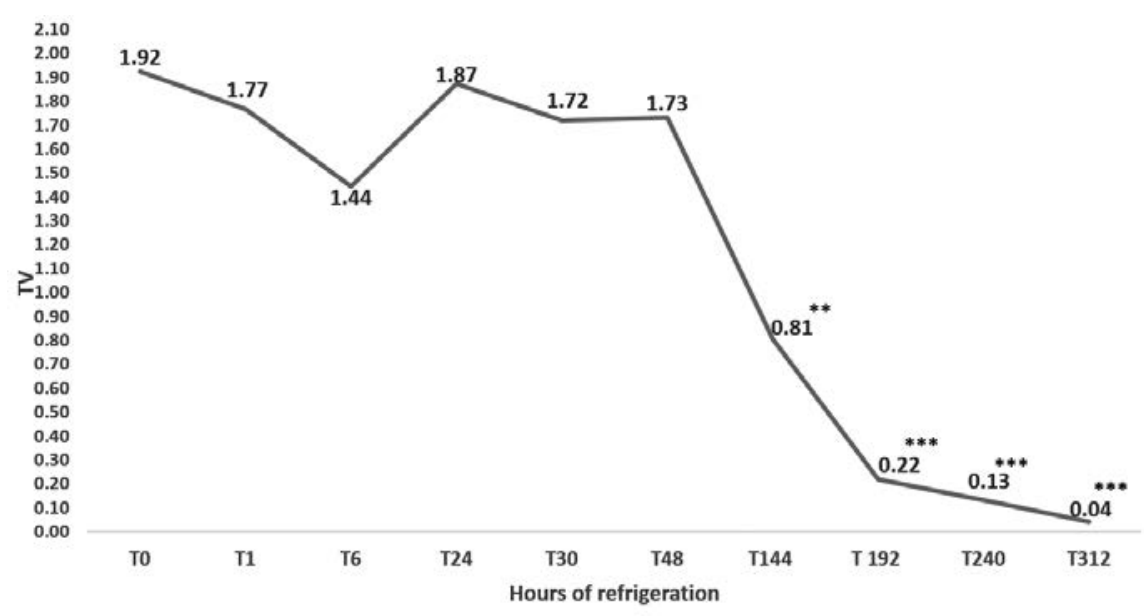

Figure 4. Changes in TV (relative fluorescence values of the sample/relative fluorescence values of positive control) with longer refrigeration time. Statistically significant: ${ }^{*} \mathbf{P}<0.05$; ${ }^{* *} \mathbf{P}<0.001 ;{ }^{* * *} \mathbf{P}<0.0001$. 
differences between the fluorescence values at higher concentrations (from $1.5^{*} 10^{7}$ to $1.5^{*} 10^{4}$ ); however, the values were drastically decreased between 1500-150 CFU/25 mL (Figure 5). The ELFA method showed $100 \%$ sensitivity (IC 95\% 0.971.00 ), specificity (IC 95\% 0.98-1.00), and accuracy (IC 95\% 0.99-1.00). Analysis of the 70 milk samples showed concordant results for 42 samples that tested negative and 28 positive; analysis of the 34 cheese samples showed that 17 tested positive and 17 negative. ELFA and reference method showed the same results for all samples under study. The associated test P-value of Fisher's exact test was $\mathrm{P}=1$ for all relative detection level levels, suggesting a $100 \%$ probability that the positive samples were correctly identified.
Between 1 January 2014 and 31 December 2016, we used the ELFA method for raw milk sample analysis in our food control laboratory. Out of the 460 samples analyzed, $5.0 \%(23 / 460)$ tested positive at ELFA screening and were subsequently confirmed by isolation of the bacterial strain; in all cases $C$. jejuni was isolated.

\section{Conclusions}

Several microorganisms can be present in dairy products (e.g., Campylobacter spp., Salmonella spp., Listeria monocytogenes, verocytotoxin-producing Escherichia coli) coming from animal reservoirs, and which can outcome important sources of foodborne illness.

A

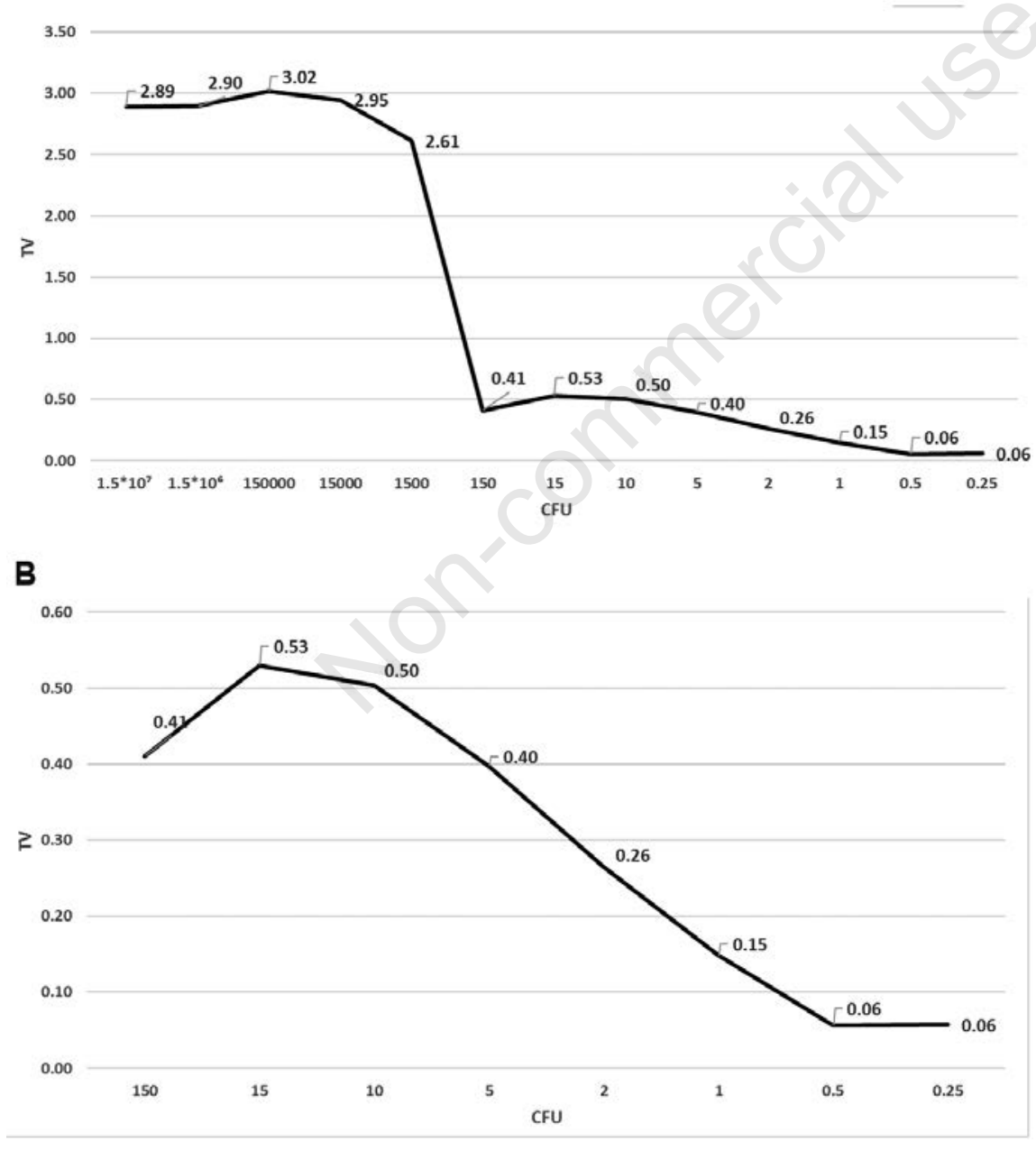

Figure 5. Limit of detection (LOD). Data are expressed in TV (relative fluorescence values of the sample/relative fluorescence values of positive control). A) Campylobater concentrations were detectable from $1.5^{*} 107$ to $1 \mathrm{CFU} / 25 \mathrm{~g}$. Concentrations were drastically decreased between 1500-150 CFU/25 mL but were detected until 1 CFU/25 g. B) Concentrations $<0.10$ TV were considered negative.

However, one of the major disadvantages of DNA based techniques is their inability to distinguish between DNA from viable and dead cells (Nocker et al., 2006), which is probably the most important obstacle for implementation of these methods in routine applications.

Results of the present study suggest that ELFA correctly identified Campylobacter in the artificially contaminated samples; its performance was comparable to that of the reference analytical method (ISO 10272$1: 2006)$ as validated with the standard procedure. Validation of the ELFA method for the detection of Campylobacter spp. in official controls is a fundamental step to reduce the lengthy analysis time and the costs of conventional methods. With the ELFA method, we were able to shorten analysis time for the detection of Campylobacter spp., which was particularly advantageous for the analysis of suspected samples and it may benefit the entire food trade.

\section{References}

Botteldoorn N, Van Coillie E, Piessens V, Rasschaert G, Debruyne L, Heyndrickx M, Herman L, Messens W, 2008. Quantification of Campylobacter spp. in chicken carcass rinse by real-time PCR. J Appl Microbiol 105:1909-18.

EFSA (European Food Safety Authority) and ECDC (European Centre for Disease Prevention and Control), 2017. The European Union summary report on trends and sources of zoonoses, zoonotic agents and food-borne outbreaks in 2016. EFSA J 15:5077, 228 pp.

EFSA and ECDC (European Food Safety Authority and European Centre for Disease Prevention and Control), 2015. The European Union summary report on trends and sources of zoonoses, zoonotic agents and food-borne outbreaks in 2014. EFSA J 13:4329.

EFSA Journal, 2012. EU Summary Report on Trends and Sources of Zoonoses, Zoonotic Agents and Food-borne Outbreaks in 2010. EFSA J 10:2597.

Haughton PN, Lyng J, Cronin D, Fanning S, Whyte P, 2012. Effect of crust freezing applied alone and in combination with ultraviolet light on the survival of Campylobacter on raw chicken. Food Microbiol 32:147-52.

Melero B, Cocolin L, Rantsiou K, Jaime I, Rovira J, 2011. Comparison between conventional and qPCR methods for enumerating Campylobacter jejuni in a poultry processing plant. Food Microbiol 28:1353-8. 
Nocker A, Cheung C, Camper A, 2006. Comparison of propidium monoazide with ethidium monoazide for differentiation of live vs. dead bacteria by selective removal of DNA from dead cells. J Microbiol Methods 67:310-20.

O'Keeffe M, 2000. Residue analysis in food. Principles and applications. 1st ed., Harwood Academic Publishers, O'Keeffe M, Amsterdam (The Netherlands).

Razzuoli E, Villa R, Amadori M, 2013. IPEC-J2 cells as reporter system of the anti-inflammatory control actions of interferon-alpha. J Interferon Cytokine Res 33:597-605.

Razzuoli E, Villa R, Sossi E, Amadori M, 2011. Reverse transcription real-time PCR for detection of porcine interferon $\alpha$ and $\beta$ genes. Scand J Immunol 74:4128.

Rodrigues RC, Pocheron AL, Hernould M, Haddad N, Tresse O, Cappelier JM,
2015. Description of Campylobacter jejuni Bf, an atypical aero-tolerant strain. Gut Pathog 19:7-30.

Rohonczy K, Zoller L, Hermann Z, Fodor A, Mráz B, Tabajdi-Pintér V, 2014. Comparison of an automated ELFA and two different real-time PCR techniques for Salmonella detection in poultry samples. Acta Microbiol Immunol Hung 61:261-72.

Saiyudthong S, Phusri K, Buates S, 2015. Rapid Detection of Campylobacter jejuni, Campylobacter coli, and Campylobacter lari in Fresh Chicken Meat and By-Products in Bangkok, Thailand, Using Modified Multiplex PCR. J Food Prot 78:1363-9.

Stefan A, Scaramagli S, Bergami R, Mazzini C, Barbanera M, Perelle S, Fach P, 2007. Real-time PCR and enzyme-linked fluorescent assay methods for detecting Shiga-toxin-producing Escherichia coli in mincemeat samples. Can J Microbiol
53:337-42.

Stern NJ, Robach MC, 2003. Enumeration of Campylobacter spp. in broiler faeces and in corresponding processed carcasses. J Food Prot 66:1557-63.

Talaat AM, Howard ST, Hale W, Lyons R, Garner H, Johnston SA, 2002. Genomic DNA standards for gene expression profiling in Mycobacterium tuberculosis. Nucleic Acids Res 30:e104.

Ueda S, Kuwabara Y. Evaluation of an enzyme-linked fluorescent assay for the detection of Listeria monocytogenes from food. Biocontrol Sci 2010;15:91-5. Vencia W, Nogarol C, Bianchi DM, Gallina S, Zuccon F, Adriano D, Gramaglia M, Decastelli L, 2014. Validation according to ISO 16140:2003 of a commercial realtime PCR-based method for detecting Campylobacter jejuni, C. coli, and C. lari in foods. Int J Food Microbiol 177:7880 